\title{
The IL-6 Paradox: Context Dependent Interplay of SOCS3 and AMPK
}

\author{
Jessica L Sarvas ${ }^{2}$, Neelam Khaper ${ }^{1,2 *}$ and Simon J Lees ${ }^{1-3 *}$
}

${ }^{1}$ Medical Sciences Division, Northern Ontario School of Medicine, Thunder Bay, Canada

${ }^{2}$ Department of Biology, Lakehead University, Thunder Bay, Canada

${ }^{3}$ Health and Exercise Science, Colorado State University, Fort Collins, USA

\begin{abstract}
Insulin resistance is the principle step towards the progression of type 2 diabetes, and has been linked to increased circulating levels of cytokines, leading to chronic low-grade inflammation. Specifically, in chronic disease states increased IL-6 is thought to play a critical role in the regulation of insulin resistance in the peripheral tissues, and has been used as a marker of insulin resistance. There is also an endogenous up-regulation of IL- 6 in response to exercise, which has been linked to improved insulin sensitivity. This leads to the question "how can elevated IL-6 lead to the development of insulin resistance, and yet also lead to increased insulin sensitivity?" Resolving the dual role of IL-6 in regulating insulin resistance/sensitivity is critical to the development of potential therapeutic interventions. This review summarizes the literature on the seemingly paradoxical role of elevated IL- 6 on insulin signalling, including the activation of AMPK and the involvement of leptin and SOCS3.
\end{abstract}

Keywords: Type 2 diabetes; Insulin resistance; Insulin sensitivity; Chronic low-grade inflammation; SOCS3; AMPK; Leptin signalling

Abbreviations: T2D: Type 2 Diabetes; IL-6: Interleukin-6; HFD: High Fat Diet; IR: Insulin Receptor; IRS-1 and IRS-2: Insulin Receptor Substrate 1 and 2; PI3 kinase: Phosphoinositide 3 Kinase; GLUT-4: Glucose Transporter 4; STAT3: Signal Transducer and Activator of Transcription 3; SOCS3: Suppressor of Cytokine Signalling 3; AMPK: AMP Activated Protein Kinase

\section{Introduction}

It is estimated that 347 million people worldwide have diabetes, with approximately $90 \%$ of those cases being Type 2 Diabetes (T2D) (World Health Organization). There are many grave pathophysiological outcomes of T2D, leading to increased morbidity and mortality. T2D leads to a greater incidence of tissue damage leading to complications in the cardiovascular system, kidneys, retina, and peripheral nervous system. Furthermore, the World Health Organization projects that deaths attributed to diabetes will double between 2005 and 2030. Altered function of insulin at peripheral tissues leads to insulin resistance in skeletal muscle, liver, and adipose tissue, which is critical to the development and progression of T2D.

Insulin is an anabolic hormone that is released by the $\beta$-cells in the pancreas to maintain glucose homeostasis within the body. The insulin signaling cascade begins when insulin binds to the Insulin Receptor (IR) on the cell membrane. Insulin binding results in autophosphorylation and activation of the IR beta subunit. Once activated, IR phosphorylates and activates several molecules, including the Insulin Receptor Substrate (IRS) proteins 1 and 2. IR binds to IRS-1 and IRS-2 through the Pleckstrin Homology (PH), and Phosphotyrosine Binding (PTB) domains [1]. IRS-1 functions primarily in skeletal muscle and adipose tissues, whereas IRS-2 functions primarily in the liver [2]. The tyrosine phosphorylation of IRS proteins activates binding sites for Src Homology 2 (SH2) domain proteins including Phosphoinositide 3-kinase (PI3 kinase) [3]. IRS phosphorylates PI3 kinase by binding to the regulatory subunit $\mathrm{p} 85$, and generates membrane phosphatidylinositol-3,4,5-Trisphosphate (PIP3). In turn, PIP3 recruits and activates phosphoinositide 3-dependent kinase 1 and 2, protein kinase $C$, and Akt leading to subsequent phosphorylation of downstream targets such as mammalian Target of Rapamycin (mTOR), and glycogen synthase kinase- $3 \beta$. Insulin is released in response to increased levels of circulating glucose, causing a coordinated response in peripheral tissues with the overall goal to take up and store glucose. Insulin stimulates glucose uptake in skeletal muscle and adipose tissue and causes translocation of Glucose Transporter 4 (GLUT-4) vesicles to the plasma membrane to facilitate glucose transport into the cells (Figure 1). In the liver, insulin signaling regulates gluconeogenesis by inhibiting key enzymes, resulting in reduced hepatic glucose output. Although skeletal muscle accounts for approximately $75 \%$ of whole body insulinstimulated glucose uptake, glycogen synthesis is also stimulated to store large amounts of glucose in the liver [4]. The effects of insulin on glucose metabolism are complex and highly regulated. Adding to this complexity, these signaling pathways can be altered or influenced by various pathophysiological conditions, such as inflammation, infection, and obesity.

The current literature provides evidence that elevated IL- 6 plays an important role both in the development of insulin resistance, and as a mediator of increased exercise induced insulin sensitivity. However, there are still many gaps in knowledge related to these context dependent physiological outcomes of elevated IL-6. This review summarizes the literature on the paradoxical role of elevated IL-6 on insulin signaling, and highlights novel questions concerning the relationship between IL-6, SOCS3, and AMPK.

\section{Chronic Low-grade Inflammation vs. Acute Inflamma- tion}

Interleukin-6 (IL-6) is a pleiotropic cytokine that is secreted by

*Corresponding authors: Dr. Neelam Khaper, 955 Oliver Road, Thunde Bay, Ontario, Canada, Tel: 1+807 766 7374; Fax: 1+807 766 7362; E-mail: nkhaper@nosm.ca

Dr. Simon Lees, 955 Oliver Road, Thunder Bay, Ontario, Canada, Tel: 1+807 766 7435; Fax: 1+807-766 7362; E-mail: simon.lees@nosm.ca

Received April 08, 2013; Accepted May 19, 2013; Published May 24, 2013

Citation: Sarvas JL, Khaper N, Lees SJ (2013) The IL-6 Paradox: Context Dependent Interplay of SOCS3 and AMPK. J Diabetes Metab S13: 003. doi:10.4172/2155-6156.S13-003

Copyright: @ 2013 Sarvas JL, et al. This is an open-access article distributed unde the terms of the Creative Commons Attribution License, which permits unrestricted use, distribution, and reproduction in any medium, provided the original author and source are credited. 
Citation: Sarvas JL, Khaper N, Lees SJ (2013) The IL-6 Paradox: Context Dependent Interplay of SOCS3 and AMPK. J Diabetes Metab S13: 003. doi:10.4172/2155-6156.S13-003

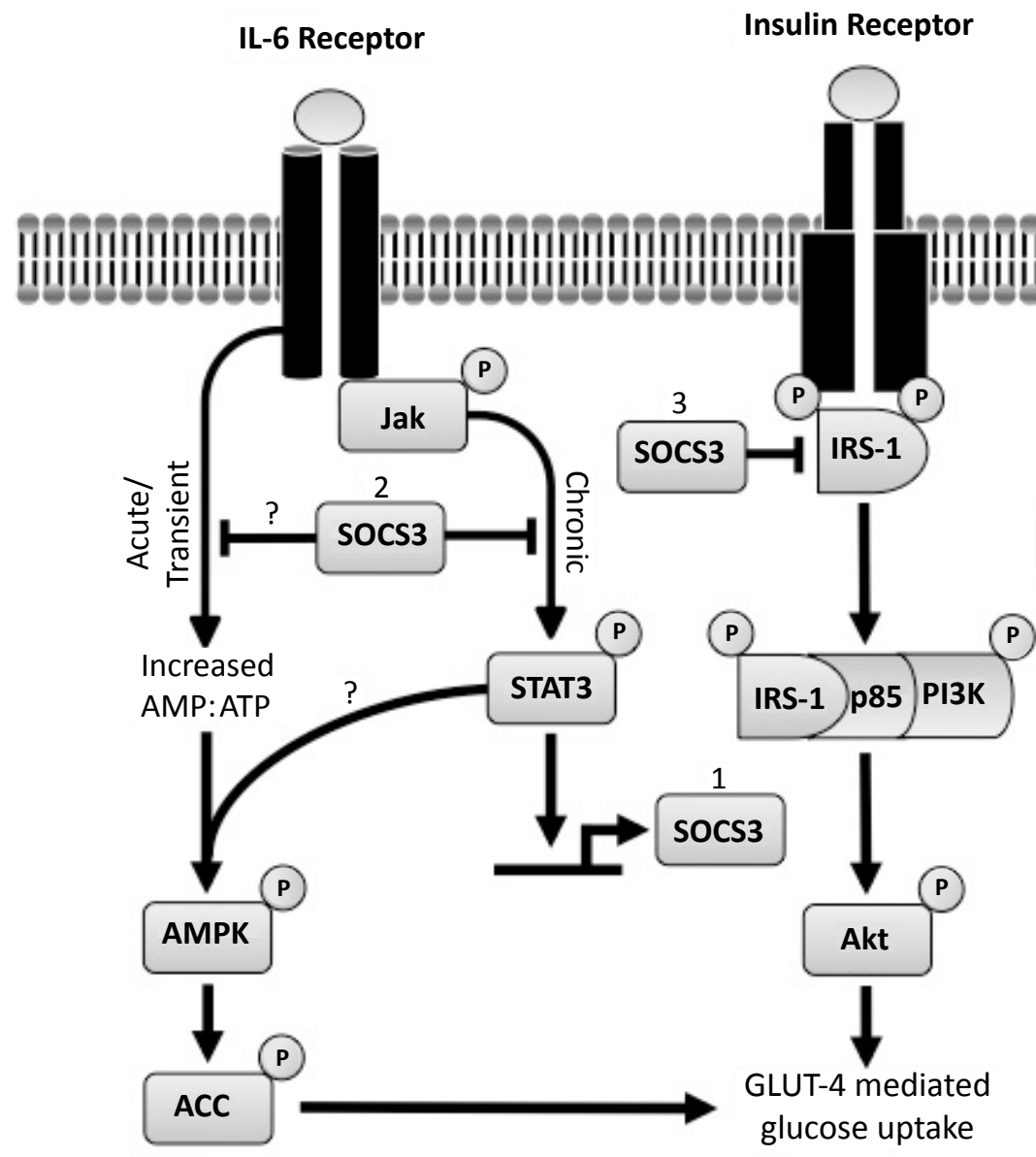

\section{Leptin Receptor}

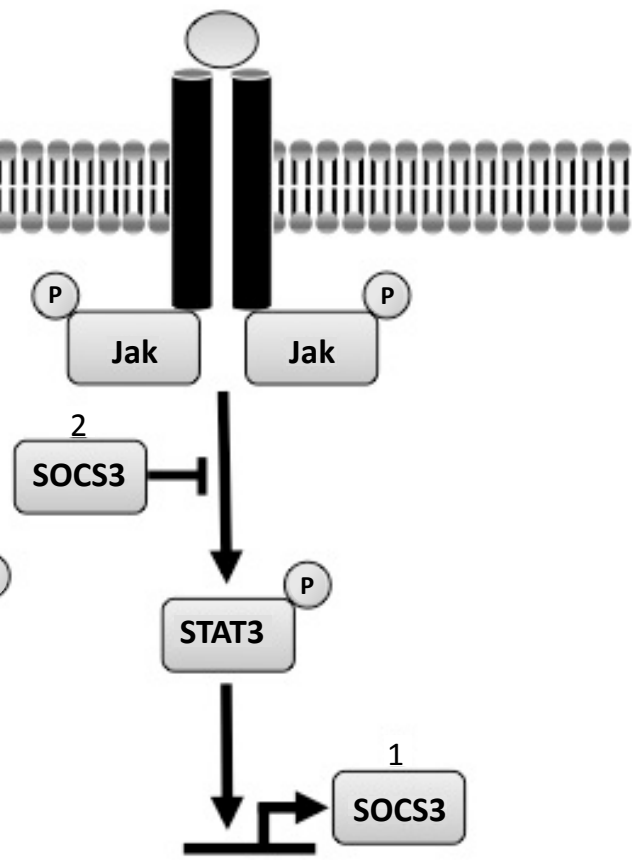

1. STAT3 activation leads to increased SOCS3 expression

2. Increased SOCS3 exerts negative feedback on Jak/STAT signaling

3. Increased SOCS3 negatively regulates insulin signaling

? Acute IL-6 increases AMPK activity, potentially involving STAT3. However, increased SOCS3 may inhibit IL-6 induced AMPK activation

Figure 1: IL-6, insulin, and leptin signaling in skeletal muscle. Chronic low-grade inflammation is associated with increased levels of IL-6, which leads to increased phosphorylation of STAT3, and subsequent increased SOCS3 expression. Increased SOCS3 mediates the inhibitory effects of IL-6 on insulin signaling and glucose uptake. SOCS3 directly disrupts insulin signaling by binding to IR and preventing interaction with IRS-1 (primarily in skeletal muscle and adipose tissue) I IRS-2 (primarily in the liver), and may target IRS-1/IRS-2 for degradation. Disrupting the early signaling events also has downstream effects on other proteins in the insulin pathway including PI3K and Akt, ultimately leading to insulin resistance and attenuated GLUT-4 mediated glucose uptake. Chronically elevated leptin levels also leads to increased SOCS3 expression, which can also directly inhibit insulin mediated glucose uptake. In addition, SOCS3 can have indirect effects on glucose uptake; increased SOCS3 leading to leptin resistance, and impaired leptin mediated AMPK activation. In contrast, acute/transient IL-6 elevations in response to exercise do not cause sustained increased SOCS3 expression, but cause increased insulin sensitivity in peripheral tissues by increased AMPK activity and subsequent increased glucose uptake. IL-6 mediated activation of AMPK in response to exercise is blunted in chronic inflammatory states. Since IL-6 is required for exercise-induced AMPK activation and obesity results in a blunted exercise-induced activation of AMPK, it is possible that increased SOCS3 may cause IL-6 resistance, which results in diminished AMPK activity and increased insulin resistance. IL-6: Interleukin-6; STAT3: Signal Transducer and Activator of Transcription 3; SOCS3: Suppressor of Cytokine Signaling 3; IR: Insulin Receptor; IRS: Insulin Receptor Substrate; PI3K: Phosphoinositide 3 Kinase; GLUT-4: Glucose Transporter 4; AMPK: AMP activated Protein Kinase

and acts on a wide variety of tissues and cells. IL- 6 mediates several steps in the activation of inflammatory responses, by regulating the synthesis of pro-inflammatory cytokines [5]. However, IL-6 also promotes the synthesis of anti-inflammatory cytokines such as, IL-1 receptor antagonist and IL-10 [5,6]. Therefore, IL-6 exhibits both pro- and anti-inflammatory properties, and there seems to be context dependent effects. The plasma levels of IL-6 in healthy humans are typically less than $5 \mathrm{pg} / \mathrm{ml}$ [7] (Table 1). Although many different cell types are capable of producing IL-6, the release differs under varying physiological conditions within the body. In healthy humans, adipose tissue releases $10-35 \%$ of IL-6 in basal circulating levels [8]. Immune cells, specifically macrophages that are present within adipose tissue are responsible for releasing the majority of IL-6 from this tissue [9]. In obesity, increased numbers of macrophages begin to infiltrate the white adipose tissue, and the macrophage content correlates positively with adiposity and adipocyte size [10]. This increased number of 


\begin{tabular}{|c|c|c|c|c|}
\hline Inflammatory Marker & Normal & Obesity & Sepsis & Exercise \\
\hline IL-6 & $<5$ pg/ml [7,12,97,103-109] & $1.5-38 \mathrm{pg} / \mathrm{ml}[105,106,110-113]$ & $3.5-16000 \mathrm{pg} / \mathrm{ml}$ [114- 16] & $\begin{array}{l}\sim 100 \text { fold elevation in resting } \\
\text { concentration }[6,16-18,97]\end{array}$ \\
\hline TNF- $\alpha$ & $\begin{array}{l}<3.5 \mathrm{pg} / \mathrm{ml} \\
{[12,16,103,106,116]}\end{array}$ & $1.8-88 \mathrm{pg} / \mathrm{ml}[106,110,113]$ & $\begin{array}{l}\text { Undetectable-1000 pg/ml } \\
\text { [117] }\end{array}$ & $\sim 2$ fold elevation in resting concentration $[6,16]$ \\
\hline IL-10 & $<3.0 \mathrm{pg} / \mathrm{ml}[103,109,118]$ & $0.35-10 \mathrm{pg} / \mathrm{ml}[108,111,112,118]$ & $\begin{array}{l}\text { Undetectable- } 1700 \mathrm{pg} / \mathrm{ml} \\
\text { [119] }\end{array}$ & $\begin{array}{l}\sim 8-27 \text { fold elevation in resting concentration } \\
{[6,16]}\end{array}$ \\
\hline CRP & $<10 \mathrm{mg} / \mathrm{l}[107]$ & $\begin{array}{l}1.3-8.5 \mathrm{mg} / \mathrm{l} \\
{[105,106,108,110,112]}\end{array}$ & $>10 \mathrm{mg} / \mathrm{l}[120]$ & $\begin{array}{l}\text { Up to } 100 \text { fold elevation in resting concentration } \\
{[6,16,121]}\end{array}$ \\
\hline
\end{tabular}

IL-6: Interleukin-6; TNF-a: Tumor Necrosis Factor alpha; IL-10: Interleukin-10; CRP: C Reactive Protein

Table 1: Plasma levels of inflammatory markers in humans under varying physiological and pathophysiological conditions.

macrophages leads to increased production of C-reactive protein, and inflammatory cytokines, including TNFa, IL-1 $\beta$ and IL-6 [11]. Additionally, it was found that TNFa and IL-6 were more highly expressed in macrophages compared to adipocyte cells in adipose tissue obtained from an obese mouse model $(o b / o b)$. Therefore, obesity has been characterized as a state of chronic low-grade inflammation, due to the increased secretion and subsequent $\sim 2$-3-fold elevation in systemic inflammatory markers from macrophages in the adipose tissue $[10,12]$ (Table 1$)$.

In contrast to chronically elevated IL-6, there can also be elevated IL-6 in response to acute infection, sepsis or exercise. An acute phase response results in the release of similar inflammatory markers that are seen in chronic low-grade inflammation, however, the acute circulating levels of these markers are much higher than levels associated with systemic inflammation. An acute transient increase in inflammatory markers also occurs during physical activity [11]. While it is true that eccentric contractions cause damage to skeletal muscle and can elicit an inflammatory response, there is also an acute transient increase in cytokine levels in response to physical activity in undamaged muscle [13]. However, unlike sepsis and infection, pro-inflammatory cytokines, TNF- $\alpha$ and IL-1 $\beta$, do not typically increase $[14,15]$. It has been reported that plasma IL-6 concentrations increased approximately 100 fold during exercise, and the magnitude of increase in IL- 6 depends on the duration and intensity of the exercise [16-18] (Table 1). Increases in IL-6 mRNA and protein were found in skeletal muscle during exercise, and the skeletal muscle cells produced enough IL- 6 to account for the large increase in plasma IL-6 levels [19-21]. In contrast to chronic lowgrade inflammation, infection and sepsis, it was shown that this acute increase in IL-6 levels was not due to activation of macrophages [22].

Although both chronic low-grade inflammation and exercise result in increased plasma IL-6 levels, there are important differences between the two conditions. Chronic low-grade inflammation is characterized by a slight yet significant systemic increase in IL-6 levels, whereas exercise results in an acute and transient increase in IL-6 levels. During chronic low-grade inflammation the increased IL-6 is released primarily from macrophages in adipose tissue $[10,12]$, while during exercise the IL- 6 is released from skeletal muscle $[19,23]$. IL-6 released from muscle during exercise allows accumulation within the skeletal muscle compartment and potentially increases specificity of IL-6 signaling at skeletal muscle, acting in an autocrine/paracrine fashion. This may also account for differences observed in the effects of IL-6 in response to exercise (acute/ transient) versus chronic low-grade inflammation. Although IL-6 released from skeletal muscle will enter the circulation, and acts in an endocrine manner during exercise, the elevated IL- 6 is only transient, and therefore, does not have the negative effects on tissues seen with chronically elevated IL- 6 levels. The differences between these chronic and acute IL- 6 elevations may be important with respect to the effects that the increased IL- 6 has on target tissues, and more specifically, the effects on insulin signaling within these tissues.

\section{IL-6 Increases SOCS3 Expression}

IL-6 initiates cell signaling by binding to the IL-6 Receptor (IL6R), which is also known as a type I cytokine receptor. The IL-6R exists as membrane bound and soluble receptors and IL- 6 regulates the inflammatory state by coordinated signaling through both forms. The interaction between IL- 6 and IL-6R forms a heterodimer with a non-ligand binding membrane glycoprotein, gp130 [24]. The complex formed between IL-6/IL-6R and gp130 activates the Janus kinasesignal transducer and activator of transcription (Jak/STAT) signal transduction pathway in IL-6 target cells, leading to the phosphorylation of the cytoplasmic portion of gp130 [25]. The phospho-tyrosine residues on gp130 are docking sites for STAT (signal transducer and activator of transcription) proteins, which are able to bind to these docking sites via SH2 domains. Several studies, both in vitro and in vivo, have shown that IL-6 stimulation increases the phosphorylation of STAT3 proteins. Activated STAT3 is translocated to the nucleus, where it is able to regulate the transcription of IL- 6 target genes. IL- 6 mediated Jak/STAT signaling can be induced rapidly, and results in increased phosphorylation of STAT3 under acute inflammatory conditions [2629] (Figure 1).

As a negative feedback control, activated STAT proteins induce the expression of Suppressor of Cytokine Signaling (SOCS) proteins, which inhibit signaling events in response to various cytokines, including IL-6, IL-10, and interferon gamma. SOCS3 is able to down regulate IL-6 signaling by exerting negative feedback control on the Jak/STAT pathway through various mechanisms [30-32]. Both in vivo and in vitro studies provide evidence that elevated circulating levels of IL-6 result in increased expression of SOCS3 proteins in skeletal muscle [26,3335], liver [36], and adipose tissue [26,37]. Consequently, this increase in SOCS3 expression has various important downstream effects on the insulin signaling pathway in these tissues.

\section{SOCS3 and Insulin Resistance}

Chronically elevated IL-6 leads to increased expression of SOCS3 proteins in skeletal muscle, liver and adipose tissue. This increased expression of SOCS3 mediates the inhibitory effects of IL- 6 on insulin signaling and glucose metabolism $[36,38,39]$. It has been shown that insulin resistance increases following SOCS3 adenoviral [36] and transgene [38] overexpression in liver and adipose tissue. SOCS3 adenoviral overexpression in the liver of $d b / d b$ obese mice leads to increased plasma insulin concentrations, glucose intolerance, and insulin resistance. Furthermore, when these mice were given antisense treatment for SOCS3 protein, insulin sensitivity improved [39]. Similarly, after a muscle specific deletion of SOCS3, whole body glucose tolerance and insulin sensitivity increased. This was due to enhanced glucose uptake into skeletal muscle [40]. Additionally, it 
was found that insulin sensitivity increased following an adipose tissue specific SOCS3 deletion, suggesting that SOCS3 negatively regulates insulin signaling $[37,41]$. Although it has been demonstrated that increased SOCS3 expression causes insulin resistance in multiple tissues, the mechanisms by which SOCS3 exerts these effects are less clear. There is a large body of evidence supporting that SOCS3 disrupts insulin signaling by binding to specific sites on IR, and IRS-1/IRS-2, as well as targeting IRS-1/IRS-2 for degradation [36]. Disrupting these early signaling events also has downstream effects on other important proteins in the insulin pathway, including PI3 kinase and Akt.

It has been demonstrated that the $\beta$ subunit of IR and SOCS3 co-immunoprecipitated in muscle lysates, and adenoviral mediated overexpression of SOCS3 resulted in decreased insulin stimulated phosphorylation of both IRS-1 and IRS-2 [36]. Since the decreased phosphorylation of IRS-1 and IRS-2 occurred without a decrease in IR phosphorylation, SOCS3 may bind to residues on IR that are involved in IR/IRS binding. Tyrosine 960 of IR is an important residue in IR/IRS binding [42], and when mutated to phenylalanine, SOCS3 was unable to bind to the $\beta$ subunit of IR [36]. This finding suggests that when SOCS3 binds to the IR, it inhibits IR/IRS1 interaction, and consequently, disrupts insulin signaling. Co-immunoprecipitation of SOCS3 with both the $\beta$ subunit of IR and IRS- 1 was increased in skeletal muscle from rats fed High Fat Diets (HFD), and obese Zucker rats compared to the control rats [43,44]. HFDs cause elevated IL-6, which leads to increased SOCS3 expression, and acts as barrier between IR and IRS-1 binding. Consequently, insulin stimulated tyrosine phosphorylation of IRS-1 was decreased in both the HFD rats and obese Zucker rats compared to the control rats $[43,44]$. The decreased IRS-1 phosphorylation caused decreased activity and phosphorylation of PI3 kinase, and increased insulin resistance [44]. Following a skeletal muscle specific SOCS3 deletion, there was no difference in IR, IRS-1, and Akt protein expression. However, IRS-1 association with the p85 subunit of PI3 kinase and Akt phosphorylation increased in SOCS3 deficient mice after insulin stimulation [40]. These studies suggest that muscle specific SOCS3 deletion improves insulin sensitivity in mice fed a HFD.

Along with skeletal muscle, increased SOCS3 expression can also induce insulin resistance in the liver. When the HepG2 cells (human liver cell line) and primary hepatocytes were treated first with IL-6 and then insulin, SOCS3 expression increased, and tyrosine phosphorylation of IRS-1 and IRS-2 were decreased, but the phosphorylation of IR did not differ $[45,46]$. Similar to skeletal muscle, it was found that SOCS3 co-immunoprecipitated with the $\beta$ subunit of IR in liver lysates, and these findings suggest that SOCS3 attenuates insulin signaling by inhibiting IR/IRS binding in the liver [36]. Increased SOCS3 suppressed IRS-1 association with the p85 subunit of PI3 kinase, and attenuated Akt phosphorylation $[39,45,46]$. When treated with antisense oligonucleotides against SOCS3, the phosphorylation of both IRS-1 and IRS- 2 was restored, and the activity of PI3 kinase and Akt was improved [39]. In a Lipopolysaccharide (LPS) model for sepsis, SOCS3 protein expression was increased in the liver, which resulted in a drastic decrease in IRS-1 and IRS-2 phosphorylation in response to insulin. Furthermore, insulin stimulated PI3 kinase and Akt activity were both significantly decreased [36]. However, in contrast to other studies, IR phosphorylation was decreased in the mice that were treated with LPS. It should be noted that LPS injection simulates endotoxemia in the liver tissue, and this is a severe model of systemic inflammation compared to chronic low-grade inflammation. This may account for discrepancies in results between studies using these different models of inflammation.
In addition to decreased tyrosine phosphorylation of IRS-1 and IRS-2, SOCS has also been shown to mediate the degradation of these proteins. Adenoviral mediated expression of SOCS1 in liver lysates resulted in reduced levels of IRS- 1 and IRS- 2 proteins, and these levels returned to normal when SOCS1 was no longer detected [47]. SOCS proteins contain a highly conserved binding domain known as the SOCS box [30-32]. The SOCS box has an Elongin $C$ binding motif that can form a complex with Elongin B [48]. This Elongin BC complex assembles an E3 ubiquitin ligase complex, which can degrade IRS-1 and IRS-2 proteins [49]. The deletion of SOCS box residues resulted in no reduction of IRS-1 and IRS-2 proteins levels when SOCS1 was expressed [47]. Although these results were only shown with SOCS1, the Elongin $\mathrm{C}$ binding motif is present in the SOCS box of both SOCS1 and SOCS3. Therefore, under certain circumstances degradation via the E3 ubiquitin ligase complex is a plausible explanation for the reduced IRS-1 and IRS-2 protein levels following SOCS3 expression [36].

Along with skeletal muscle and liver, SOCS3 is also a negative regulator of insulin signaling in adipose tissue. When SOCS3 was overexpressed in primary adipocytes or adipose tissue, insulin stimulated IRS-1 tyrosine phosphorylation, PI3 kinase activation of p85 subunit, and Akt phosphorylation decreased resulting in increased insulin resistance $[38,50]$. There was also a significant reduction in IRS1 protein levels, which suggests that SOCS3 may be capable of degrading IRS-1 via ubiquitin ligase in adipose tissue [38,50]. SOCS3 deficient mouse embryonic fibroblasts, differentiated into adipocytes, showed increased IRS- 1 and IRS- 2 tyrosine phosphorylation compared to wild type adipocytes when stimulated with insulin [37]. Additionally, in the SOCS3 deficient adipocytes, p85 subunit binding to IRS-1, PI3 kinase activity, and glucose uptake were all increased. During chronic insulin treatment, which simulates conditions that lead to increased SOCS3 expression, IRS-1 protein levels were decreased in wild type adipocytes, which were not seen in the SOCS3 deficient adipocytes [37]. HFD mice with an adipose tissue specific deletion SOCS3 deletion (AKO) had increased glucose infusion rate with hyperinsulinaemic-euglyceamic clamp tests compared to the control mice [41]. Following a bolus of insulin, there was decreased IRS-1 tyrosine phosphorylation and IRS-1 protein levels in the HFD control mice compared to the HFD AKO mice. These findings demonstrate that the deletion of SOCS3 can protect against HFD induced insulin resistance in adipose tissue.

Collectively, these studies provide evidence that SOCS3 is a negative regulator of insulin signaling in skeletal muscle, liver, and adipose tissue. The ability of SOCS3 to inhibit insulin signaling suggests that these proteins influence energy balance and glucose homeostasis within the body. In support of this, SOCS3 is also known to have a role in the development of leptin resistance.

\section{SOCS3 and Leptin Resistance}

Leptin is a hormone secreted by adipocytes that regulates energy balance and caloric intake in the body. The leptin receptor $(\mathrm{LRb})$ is a class I cytokine receptor, and is membrane bound as a homodimer [51]. In the hypothalamus, leptin binds to its receptor on the plasma membrane, and this leads to tyrosine phosphorylation of Jak2, and subsequent tyrosine phosphorylation of LRb [52,53]. Phosphorylated LRb binds to, and activates STAT3 proteins. STAT3 activation increases Pro-opiomelanocortin (POMC) expression, as well as inhibits Neuropeptide Y (NPY) and agouti-related peptide (AgRP) activity, all resulting in appetite suppression and increased energy expenditure [54-56]. The activation of STAT3 by leptin also mediates the transcription of SOCS3 protein [57]. Similar to IL-6 
signal transduction, leptin induces SOCS3 expression, and SOCS3 then inhibits leptin signaling (Figure 1). SOCS3 inhibits leptin signaling by binding to Tyr985 on LRb, and blocking further signal transduction through STAT3, and also by inhibiting Jak2 phosphorylation $[58,59]$. Mice with haploinsufficiency of SOCS3 had lower plasma leptin levels, and had prolonged activation of STAT3 proteins compared to wild type mice when administered the same does of leptin [60]. When leptin was infused into neuron specific SOCS3 deficient mice, these mice had greater weight loss compared to the wild type mice. Furthermore, when these mice were fed a HFD, the wild type gained significantly more weight than the SOCS3 deficient mice [61]. SOCS3 mediated inhibition of leptin signaling prevents leptin from effectively modulating energy intake and suppressing appetite, and exacerbates obesity.

Under normal conditions, leptin stimulation results in increased activity of AMP activated Protein Kinase (AMPK), and downstream target acetyl-CoA carboxylase (ACC) in peripheral tissues [62]. AMPK is a regulator of cellular energy balance, and once activated switches on energy producing pathways. AMPK phosphorylates target proteins leading to increased fatty acid oxidation, glucose transport, and lipolysis in skeletal muscle, liver, and adipose tissue [63]. However, leptin failed to increase AMPK or ACC phosphorylation in rat soleus muscle following a HFD, indicating that the tissue had become leptin resistant $[63,64]$. Leptin stimulation resulted in decreased AMPK mediated Jak2, IRS-1, and Akt phosphorylation in the liver of rats fed a HFD compared to control rats [65]. Additionally, AMPK expression was decreased in the HFD liver. Leptin resistance has also been connected to increased SOCS3 mRNA and protein expression in skeletal muscle cells [66]. When SOCS3 was overexpressed in skeletal muscle, there was decreased $\alpha 2$ AMPK activity, and decreased ACC phosphorylation [67]. These results imply that increased SOCS3 can lead to the development of leptin resistance in the muscle cells.

Chronic low-grade inflammation is associated with both increased circulating IL-6 and leptin levels, and consequently increased SOCS3 expression. Therefore, SOCS3 expression has both direct and indirect effects on the pathway under these conditions. As previously discussed, SOCS3 causes insulin resistance by directly inhibiting IR and IRS-1/ IRS-2, which consequently causes decreased activity of downstream components in the insulin signaling pathway. SOCS3 can also negatively regulate leptin signaling leading to impaired leptin induced glucose uptake via AMPK, and cause subsequent interactions between the leptin and insulin signaling pathways (Figure 1). These interactions allow SOCS3 to mediate further indirect effects on insulin signaling.

\section{Exercise and Insulin Signaling}

It has been well documented that regular physical activity can alleviate or protect against T2D by enhancing insulin sensitivity in peripheral tissues [68-76]. Metformin is an antidiabetic drug that lowers fasting plasma insulin and glucose levels, and improves glucose tolerance by suppressing hepatic glucose production and increasing glucose uptake in skeletal muscle $[77,78]$. Due to the effectiveness of metformin on lowering plasma glucose concentrations, and the inexpensive cost, metformin is the most commonly prescribed drug for T2D patients [79]. Studies comparing the effectiveness of exercise, metformin and the combination treatment on insulin sensitivity have yielded interesting findings. Insulin resistant individuals were either treated with metformin, underwent a single bout of exercise, or both combined, and insulin sensitivity was measured 4 hours post exercise. Euglycemic hyperinsulinemic clamp tests found that insulin sensitivity increased by $54 \%$ in the individuals that exercised, and these changes were not seen in the metformin or combination treatments [79].
When prediabetic individuals participated in exercise training with or without metformin for 12 weeks, insulin sensitivity was increased in all treatments. However, the increased in insulin sensitivity was 25 $30 \%$ higher in the exercise without metformin treatments compared to the others [80]. Additionally, prediabetic individuals prescribed either metformin or 150 minutes of physical activity per week for approximately 3 years resulted in the incidence of diabetes being reduced by $31 \%$ and $58 \%$ in the metformin and physical activity groups respectively [81]. Life style changes associated with regular exercise and treatment with metformin both enhance insulin sensitivity, and reduced the incidence of diabetes in high risk candidates. Pharmacological agents are more often chosen as the prescribed treatment in T2D, however it has been shown that the endogenous response to exercise is more effective. It is important to understand the mechanisms behind the increase in insulin sensitivity in response to regular exercise, as well as, why these mechanisms are more effective than current pharmacological treatments.

As previously stated, IL-6 is elevated during exercise, and plasma levels increase up to 100 fold (Table 1). IL-6 infusion during exercise caused increased glucose disposal [82], and stimulated the production of anti inflammatory cytokines IL-1 receptor antagonist and IL-10. The production of IL-10 is important because it inhibits the production of pro inflammatory cytokines IL-1, TNF alpha, and IL-8 $[5,16,83]$. Furthermore, glucose uptake rate was lower in IL-6 knockout mice compared to wild type, and the knockout mice did not benefit from exercise [84]. These studies suggest that acute elevations in IL-6 increase insulin sensitivity, whereas the lack of IL-6 prevents the exercise induced increases in insulin sensitivity.

The mechanism by which elevated IL-6 improves insulin sensitivity following physical activity may involve the regulation of AMPK activity. AMPK is an evolutionary conserved $\alpha \beta \gamma$ heterotrimer that consists of an $\alpha$ catalytic subunit, and $\beta \gamma$ regulatory subunits $[85,86]$. Mice that overexpressed a skeletal muscle specific kinase dead form of AMPKa2 had reduced exercise tolerance during a single bout of exercise compared to wild type mice $[87,88]$. Additionally, AMPK $\beta 2$ knockout mice had reduced maximal exercise capacity and AMPK activity during treadmill running compared to wild type mice [89], and muscle specific $A M P K \beta 1 \beta 2$ knockout mice showed decreased AMPKa1 22 activity and AMPK phosphorylation following exercise compared to wild type mice [90]. Following muscle contraction, glucose uptake rates did not increase until the last five minutes in hind limb muscles from AMPKa2 dominant negative mice, whereas glucose uptake rates increased rapidly and remained elevated throughout the contraction period in wild type mice [91]. A similar study on AMPKa2 dominant negative mice found that contraction induced glucose uptake was reduced by $50 \%$ in extensor digitorum longus muscle compared to the wild type mice, suggesting that AMPK activity has important role in exercise induced glucose uptake [92]. However, another study found that contraction stimulated glucose uptake into tibialis anterior, extensor digitorum longus, and gastrocnemius muscles were similar in muscle specific transgenic mice with inactive AMPKa2 catalytic subunits when compared to wild type mice [93]. In order to visualize GLUT-4 translocation and localization, mice quadriceps muscle fibers were transfected with GLUT4-Enhanced Green Fluorescent Protein (EGFP). Following ablation of AMPKa2 activity in transgenic mice, GLUT4-EGFP basal localization, and contraction stimulated GLUT4EGFP translocation was similar compared to wild type mice [94]. In contrast to above, these studies suggest that AMPKa2 activation may not be required for exercise induced glucose uptake. Therefore, AMPK activity may be necessary for full activation of exercise induced glucose 
transport, but it appears there are also AMPK independent mechanisms involved in this process [92]

Several studies have shown that IL-6 is an important factor involved in exercise-mediated activation of AMPK. AMPK is activated by decreases in the energy state of the cell, or increases in the AMP: ATP ratio, and it was shown that incubation of skeletal muscle cells with IL-6 resulted in increased concentrations of AMP [95]. Incubating extensor digitorum longus muscle and cultured F442a adipocytes with IL-6 resulted in increased AMPK and ACC phosphorylation in the cells $[96,97]$. Additionally, exercise caused increased AMPK and ACC phosphorylation in skeletal muscle, liver, and adipose tissue of control mice, and these effects were diminished in IL-6 knockout mice [96,97]. IL-6 infusion into humans at a plasma concentration that mimics levels reached during strenuous exercise increased glucose disposal rate. Furthermore, L6 myotubes, when treated with IL-6, resulted in increased insulin stimulated translocation of GLUT-4 to the plasma membrane, and was accompanied by increased AMPK activity [26]. Following adenoviral mediated infection of myotubes with a dominant negative AMPK a subunit, the effect of IL- 6 on insulin stimulated GLUT-4 translocation was diminished. AMPK phosphorylation was reduced in obese rats compared to lean rats, and contraction failed to increase AMPK activity in the obese rats following exercise $[98,99]$. Similarly, HFD fed mice had reduced exercise tolerance and attenuated AMPKa2 activity during a single bout of exercise compared to chow fed mice [100]. IL-6 has been shown to be required for exercisemediated increases in AMPK activity [96,97], but it remains unclear why IL-6 is inhibited from activating AMPK in response to exercise in chronic inflammatory states. In contrast, it was found that T2D subjects had similar exercise induced AMPKa2 activity compared to non-diabetic subjects [101]. However, none of these subjects were obese, and may not be suffering from chronic low-grade inflammation in conjunction with T2D. This interpretation was supported by another study that compared AMPK activity between obese non-diabetic, nonobese T2D, and obese T2D subjects. The obese non-diabetic and obese T2D subjects showed diminished exercise induced increases in AMPK phosphorylation, AMPKa 2 activity, and total AMPK activity compared to non-obese T2D subjects [102]. Furthermore, obese non-diabetic and obese T2D subjects had attenuated increases in ACC phosphorylation compared to non-obese T2D subjects. These results indicate that the inhibition of exercise induced increases in AMPK activity occurs under obese or chronic low-grade inflammatory conditions, and that IL-6 resistance may be related to the reduced AMPK response.

\section{Conclusion}

The role of elevated IL- 6 in insulin resistance and insulin sensitivity is an active area of investigation. The current literature provides evidence that IL-6 induces insulin resistance, and that it can also improve insulin sensitivity. These studies suggest that the effects of IL-6 on insulin signaling are context dependent, and that this is a critical factor in this paradox that cannot be overlooked. Several studies have provided evidence that leptin resistance results in decreased AMPK activity, and more specifically that this resistance is mediated by increased SOCS3 expression. There are parallels between IL- 6 and leptin signaling pathways associated with insulin resistance, including coincident activation of STAT3 and SOCS3 as a common inhibitory molecule. Since it has been demonstrated that SOCS3 can cause leptin resistance, then it may be true that IL-6 resistance can also occur. Under normal physiological conditions significant IL-6 elevations occur following exercise, and then return back to basal circulating levels shortly after. These acute transient IL- 6 elevations do not cause sustained increases in SOCS3 expression but increase insulin sensitivity, and have positive effects on insulin signaling in peripheral tissues. In contrast, IL-6 is chronically elevated in pathophysiological conditions such as obesity and T2D leading to sustained increases in SOCS3. It is feasible that similar to leptin signaling increased SOCS3 may lead to IL-6 resistance by negative feedback, resulting in diminished AMPK activity (Figure 1). Understanding and resolving the intricate relationship between IL- 6 and insulin action is important for the development of treatment strategies and regimes for inflammatory diseases.

\section{Acknowledgements}

Supported by the National Institutes of Health-National Institute on Aging (R03 AG-034352, P.I., Simon J. Lees), and The Banting Research Foundation (P.I., Simon J. Lees)

\section{References}

1. Yenush L, Makati KJ, Smith-Hall J, Ishibashi O, Myers MG Jr, et al. (1996) The pleckstrin homology domain is the principal link between the insulin receptor and IRS-1. J Biol Chem 271: 24300-24306.

2. Kido Y, Burks DJ, Withers D, Bruning JC, Kahn CR, et al. (2000) Tissuespecific insulin resistance in mice with mutations in the insulin receptor, IRS-1, and IRS-2. J Clin Invest 105: 199-205.

3. Hanke S, Mann M (2009) The phosphotyrosine interactome of the insulin receptor family and its substrates IRS-1 and IRS-2. Mol Cell Proteomics 8 : 519-534.

4. Björnholm M, Zierath JR (2005) Insulin signal transduction in human skeletal muscle: identifying the defects in Type II diabetes. Biochem Soc Trans 33 354-357.

5. Starkie R, Ostrowski SR, Jauffred S, Febbraio M, Pedersen BK (2003) Exercise and IL-6 infusion inhibit endotoxin-induced TNF-alpha production in humans. FASEB J 17: 884-886.

6. Steensberg A, Fischer CP, Keller C, Møller K, Pedersen BK (2003) IL-6 enhances plasma IL-1ra, IL-10, and cortisol in humans. Am J Physiol Endocrino Metab 285: E433-437.

7. Kado S, Nagase T, Nagata N (1999) Circulating levels of interleukin-6, its soluble receptor and interleukin-6/interleukin-6 receptor complexes in patients with type 2 diabetes mellitus. Acta Diabetol 36: 67-72.

8. Mohamed-Ali V, Goodrick S, Rawesh A, Katz DR, Miles JM, et al. (1997) Subcutaneous adipose tissue releases interleukin-6, but not tumor necrosis factor-alpha, in vivo. J Clin Endocrinol Metab 82: 4196-4200.

9. Fain JN, Madan AK, Hiler ML, Cheema P, Bahouth SW (2004) Comparison of the release of adipokines by adipose tissue, adipose tissue matrix, and adipocytes from visceral and subcutaneous abdominal adipose tissues of obese humans. Endocrinology 145: 2273-2282.

10. Weisberg SP, McCann D, Desai M, Rosenbaum M, Leibel RL, et al. (2003) Obesity is associated with macrophage accumulation in adipose tissue. $\mathrm{J}$ Clin Invest 112: 1796-1808.

11. Bruunsgaard H (2005) Physical activity and modulation of systemic low-level inflammation. J Leukoc Biol 78: 819-835.

12. Kern PA, Ranganathan S, Li C, Wood L, Ranganathan G (2001) Adipose tissue tumor necrosis factor and interleukin- 6 expression in human obesity and insulin resistance. Am J Physiol Endocrinol Metab 280: E745-751.

13. Jonsdottir IH, Schjerling P, Ostrowski K, Asp S, Richter EA, et al. (2000) Muscle contractions induce interleukin-6 mRNA production in rat skeletal muscles. $J$ Physiol 528 Pt 1: 157-163.

14. Pedersen BK, Hoffman-Goetz L (2000) Exercise and the immune system: regulation, integration, and adaptation. Physiol Rev 80: 1055-1081.

15. Brandt C, Pedersen BK (2010) The role of exercise-induced myokines in muscle homeostasis and the defense against chronic diseases. J Biomed Biotechnol 2010: 520258

16. Ostrowski K, Rohde T, Asp S, Schjerling P, Pedersen BK (1999) Pro- and antiinflammatory cytokine balance in strenuous exercise in humans. J Physiol 515 : 287-291.

17. Pedersen BK, Steensberg A, Schjerling $P$ (2001) Exercise and interleukin-6. Curr Opin Hematol 8: 137-141. 
18. Pedersen BK, Steensberg A, Fischer C, Keller C, Keller P, et al. (2003) Searching for the exercise factor: is IL-6 a candidate? J Muscle Res Cell Motil 24: $113-119$

19. Steensberg A, van Hall G, Osada T, Sacchetti M, Saltin B, et al. (2000) Production of interleukin- 6 in contracting human skeletal muscles can account for the exercise-induced increase in plasma interleukin-6. J Physiol $529 \mathrm{Pt} 1$ : 237-242.

20. Pedersen BK, Febbraio MA (2012) Muscles, exercise and obesity: skeletal muscle as a secretory organ. Nat Rev Endocrinol 8: 457-465.

21. Pedersen BK (2012) Muscular interleukin-6 and its role as an energy sensor Med Sci Sports Exerc 44: 392-396.

22. Moldoveanu AI, Shephard RJ, Shek PN (2000) Exercise elevates plasma levels but not gene expression of IL-1beta, IL-6, and TNF-alpha in blood mononuclear cells. J Appl Physiol 89: 1499-1504.

23. Pedersen BK, Akerström TC, Nielsen AR, Fischer CP (2007) Role of myokines in exercise and metabolism. J Appl Physiol 103: 1093-1098.

24. Taga T, Hibi M, Hirata Y, Yamasaki K, Yasukawa K, et al. (1989) Interleukin-6 triggers the association of its receptor with a possible signal transducer, gp130. Cell 58: 573-581.

25. Heinrich PC, Behrmann I, Müller-Newen G, Schaper F, Graeve L (1998) Interleukin-6-type cytokine signalling through the gp130/Jak/STAT pathway. Biochem J 334 : 297-314.

26. Carey AL, Steinberg GR, Macaulay SL, Thomas WG, Holmes AG, et al. (2006) Interleukin-6 increases insulin-stimulated glucose disposal in humans and glucose uptake and fatty acid oxidation in vitro via AMP-activated protein kinase. Diabetes 55: 2688-2697.

27. Glund S, Deshmukh A, Long YC, Moller T, Koistinen HA, et al. (2007) Interleukin-6 directly increases glucose metabolism in resting human skeletal muscle. Diabetes 56: 1630-1637.

28. Kim TH, Choi SE, Ha ES, Jung JG, Han SJ, et al. (2013) IL-6 induction of TLR-4 gene expression via STAT3 has an effect on insulin resistance in human skeletal muscle. Acta Diabetol 50: 189-200.

29. Begue G, Douillard A, Galbes O, Rossano B, Vernus B, et al. (2013) Early activation of rat skeletal muscle IL-6/STAT1/STAT3 dependent gene expression in resistance exercise linked to hypertrophy. PLoS One 8: e57141.

30. Starr R, Willson TA, Viney EM, Murray LJ, Rayner JR, et al. (1997) A family of cytokine-inducible inhibitors of signalling. Nature 387: 917-921.

31. Endo TA, Masuhara M, Yokouchi M, Suzuki R, Sakamoto H, et al. (1997) A new protein containing an $\mathrm{SH} 2$ domain that inhibits JAK kinases. Nature 387 : 921-924.

32. Naka T, Narazaki M, Hirata M, Matsumoto T, Minamoto S, et al. (1997) Structure and function of a new STAT-induced STAT inhibitor. Nature 387: 924-929.

33. Holmes AG, Mesa JL, Neill BA, Chung J, Carey AL, et al. (2008) Prolonged interleukin- 6 administration enhances glucose tolerance and increases skeletal muscle PPARalpha and UCP2 expression in rats. J Endocrinol 198: 367-374.

34. Franckhauser S, Elias I, Rotter Sopasakis V, Ferré T, Nagaev I, et al. (2008) Overexpression of 116 leads to hyperinsulinaemia, liver inflammation and reduced body weight in mice. Diabetologia 51: 1306-1316.

35. Rieusset J, Bouzakri K, Chevillotte E, Ricard N, Jacquet D, et al. (2004) Suppressor of cytokine signaling 3 expression and insulin resistance in skeletal muscle of obese and type 2 diabetic patients. Diabetes 53: 2232-2241.

36. Ueki K, Kondo T, Kahn CR (2004) Suppressor of cytokine signaling 1 (SOCS-1) and SOCS-3 cause insulin resistance through inhibition of tyrosine phosphorylation of insulin receptor substrate proteins by discrete mechanisms. Mol Cell Biol 24: 5434-5446.

37. Shi H, Tzameli I, Bjørbaek C, Flier JS (2004) Suppressor of cytokine signaling 3 is a physiological regulator of adipocyte insulin signaling. J Biol Chem 279 : 34733-34740.

38. Shi H, Cave B, Inouye K, Bjørbaek C, Flier JS (2006) Overexpression of suppressor of cytokine signaling 3 in adipose tissue causes local but not systemic insulin resistance. Diabetes 55: 699-707.

39. Ueki K, Kadowaki T, Kahn CR (2005) Role of suppressors of cytokine signaling SOCS-1 and SOCS-3 in hepatic steatosis and the metabolic syndrome. Hepatol Res 33: 185-192.
40. Jorgensen SB, O'Neill HM, Sylow L, Honeyman J, Hewitt KA, et al. (2013) Deletion of skeletal muscle SOCS3 prevents insulin resistance in obesity. Diabetes 62: 56-64.

41. Palanivel R, Fullerton MD, Galic S, Honeyman J, Hewitt KA, et al. (2012) Reduced Socs 3 expression in adipose tissue protects female mice against obesity-induced insulin resistance. Diabetologia 55: 3083-3093.

42. White MF, Livingston JN, Backer JM, Lauris V, Dull TJ, et al. (1988) Mutation of the insulin receptor at tyrosine 960 inhibits signal transmission but does not affect its tyrosine kinase activity. Cell 54: 641-649.

43. Zolotnik IA, Figueroa TY, Yaspelkis BB 3rd (2012) Insulin receptor and IRS 1 co-immunoprecipitation with SOCS-3, and IKKa/ß phosphorylation are increased in obese Zucker rat skeletal muscle. Life Sci 91: 816-822.

44. Yaspelkis BB 3rd, Kvasha IA, Figueroa TY (2009) High-fat feeding increase insulin receptor and IRS-1 coimmunoprecipitation with SOCS-3, IKKalpha/beta phosphorylation and decreases PI-3 kinase activity in muscle. Am J Physio Regul Integr Comp Physiol 296: R1709-1715.

45. Senn JJ, Klover PJ, Nowak IA, Mooney RA (2002) Interleukin-6 induces cellular insulin resistance in hepatocytes. Diabetes 51: 3391-3399.

46. Senn JJ, Klover PJ, Nowak IA, Zimmers TA, Koniaris LG, et al. (2003) Suppressor of cytokine signaling-3 (SOCS-3), a potential mediator of interleukin-6-dependent insulin resistance in hepatocytes. J Biol Chem 278: $13740-13746$.

47. Rui L, Yuan M, Frantz D, Shoelson S, White MF (2002) SOCS-1 and SOCS-3 block insulin signaling by ubiquitin-mediated degradation of IRS1 and IRS2. J Biol Chem 277: 42394-42398.

48. Kamura T, Sato S, Haque D, Liu L, Kaelin WG Jr, et al. (1998) The Elongin $\mathrm{BC}$ complex interacts with the conserved SOCS-box motif present in members of the SOCS, ras, WD-40 repeat, and ankyrin repeat families. Genes Dev 12 3872-3881.

49. Zhang JG, Farley A, Nicholson SE, Willson TA, Zugaro LM, et al. (1999) The conserved SOCS box motif in suppressors of cytokine signaling binds to elongins $\mathrm{B}$ and $\mathrm{C}$ and may couple bound proteins to proteasomal degradation. Proc Natl Acad Sci U S A 96: 2071-2076.

50. Yang SJ, Xu CQ, Wu JW, Yang GS (2010) SOCS3 inhibits insulin signaling in porcine primary adipocytes. Mol Cell Biochem 345: 45-52.

51. Tartaglia LA (1997) The leptin receptor. J Biol Chem 272: 6093-6096.

52. Nakashima K, Narazaki M, Taga T (1997) Leptin receptor (OB-R) oligomerizes with itself but not with its closely related cytokine signal transducer gp130. FEBS Lett 403: 79-82.

53. Ghilardi N, Skoda RC (1997) The leptin receptor activates janus kinase 2 and signals for proliferation in a factor-dependent cell line. Mol Endocrinol 11: 393 399.

54. Schwartz MW, Woods SC, Porte D Jr, Seeley RJ, Baskin DG (2000) Centra nervous system control of food intake. Nature 404: 661-671.

55. Abdel-Malek ZA (2001) Melanocortin receptors: their functions and regulation by physiological agonists and antagonists. Cell Mol Life Sci 58: 434-441.

56. Benoit S, Schwartz M, Baskin D, Woods SC, Seeley RJ (2000) CNS melanocortin system involvement in the regulation of food intake. Horm Behav 37: 299-305.

57. Banks AS, Davis SM, Bates SH, Myers MG Jr (2000) Activation of downstream signals by the long form of the leptin receptor. J Biol Chem 275: 14563-14572.

58. Dunn SL, Björnholm M, Bates SH, Chen Z, Seifert M, et al. (2005) Feedback inhibition of leptin receptor/Jak2 signaling via Tyr1138 of the leptin receptor and suppressor of cytokine signaling 3. Mol Endocrinol 19: 925-938.

59. Bjørbaek C, El-Haschimi K, Frantz JD, Flier JS (1999) The role of SOCS-3 in leptin signaling and leptin resistance. J Biol Chem 274: 30059-30065.

60. Howard JK, Cave BJ, Oksanen LJ, Tzameli I, Bjørbaek C, et al. (2004) Enhanced leptin sensitivity and attenuation of diet-induced obesity in mice with haploinsufficiency of Socs3. Nat Med 10: 734-738.

61. Mori H, Hanada R, Hanada T, Aki D, Mashima R, et al. (2004) Socs3 deficiency in the brain elevates leptin sensitivity and confers resistance to diet-induced obesity. Nat Med 10: 739-743.

62. Wolsk E, Mygind H, Grøndahl TS, Pedersen BK, van Hall G (2011) The role of 
leptin in human lipid and glucose metabolism: the effects of acute recombinant human leptin infusion in young healthy males. Am J Clin Nutr 94: 1533-1544

63. Martin TL, Alquier T, Asakura K, Furukawa N, Preitner F, et al. (2006) Dietinduced obesity alters AMP kinase activity in hypothalamus and skeletal muscle. J Biol Chem 281: 18933-18941.

64. Ritchie IR, Gulli RA, Stefanyk LE, Harasim E, Chabowski A, et al. (2011) Restoration of skeletal muscle leptin response does not precede the exerciseinduced recovery of insulin-stimulated glucose uptake in high-fat-fed rats. Am J Physiol Regul Integr Comp Physiol 300: R492-500

65. Brabant G, Müller G, Horn R, Anderwald C, Roden M, et al. (2005) Hepatic leptin signaling in obesity. FASEB J 19: 1048-1050.

66. Eguchi M, Gillis LC, Liu Y, Lyakhovsky N, Du M, et al. (2007) Regulation of SOCS-3 expression by leptin and its co-localization with insulin receptor in rat skeletal muscle cells. Mol Cell Endocrinol 267: 38-45

67. Yang Z, Hulver M, McMillan RP, Cai L, Kershaw EE, et al. (2012) Regulation of insulin and leptin signaling by muscle suppressor of cytokine signaling 3 (SOCS3). PLoS One 7: e47493.

68. Ivy JL (1997) Role of exercise training in the prevention and treatment of insulin resistance and non-insulin-dependent diabetes mellitus. Sports Med 24: 321 336.

69. Borghouts LB, Keizer HA (2000) Exercise and insulin sensitivity: a review. Int J Sports Med 21: 1-12.

70. Hawley JA, Lessard SJ (2008) Exercise training-induced improvements in insulin action. Acta Physiol (Oxf) 192: 127-135.

71. Musi N, Goodyear LJ (2006) Insulin resistance and improvements in signal transduction. Endocrine 29: 73-80.

72. Hawley JA (2004) Exercise as a therapeutic intervention for the prevention and treatment of insulin resistance. Diabetes Metab Res Rev 20: 383-393.

73. Krisan AD, Collins DE, Crain AM, Kwong CC, Singh MK, et al. (2004) Resistance training enhances components of the insulin signaling cascade in normal and high-fat-fed rodent skeletal muscle. J Appl Physiol 96: 1691-1700.

74. Bradley RL, Jeon JY, Liu FF, Maratos-Flier E (2008) Voluntary exercise improves insulin sensitivity and adipose tissue inflammation in diet-induced obese mice. Am J Physiol Endocrinol Metab 295: E586-594

75. Király MA, Campbell J, Park E, Bates HE, Yue JT, et al. (2010) Exercise maintains euglycemia in association with decreased activation of c-Jun $\mathrm{NH2}$ terminal kinase and serine phosphorylation of IRS-1 in the liver of ZDF rats. Am J Physiol Endocrinol Metab 298: E671-682.

76. Puppa MJ, White JP, Velázquez KT, Baltgalvis KA, Sato S, et al. (2012) The effect of exercise on IL-6-induced cachexia in the Apc ( Min/+) mouse. J Cachexia Sarcopenia Muscle 3: 117-137.

77. DeFronzo RA, Barzilai N, Simonson DC (1991) Mechanism of metformin action in obese and lean noninsulin-dependent diabetic subjects. J Clin Endocrino Metab 73: 1294-1301.

78. Hundal RS, Krssak M, Dufour S, Laurent D, Lebon V, et al. (2000) Mechanism by which metformin reduces glucose production in type 2 diabetes. Diabetes 49: 2063-2069.

79. Sharoff CG, Hagobian TA, Malin SK, Chipkin SR, Yu H, et al. (2010) Combining short-term metformin treatment and one bout of exercise does not increase insulin action in insulin-resistant individuals. Am J Physiol Endocrinol Metab 298: E815-823.

80. Malin SK, Gerber R, Chipkin SR, Braun B (2012) Independent and combined effects of exercise training and metformin on insulin sensitivity in individuals with prediabetes. Diabetes Care 35: 131-136.

81. Knowler WC, Barrett-Connor E, Fowler SE, Hamman RF, Lachin JM, et al. (2002) Reduction in the incidence of type 2 diabetes with lifestyle intervention or metformin. N Engl J Med 346: 393-403.

82. Febbraio MA, Hiscock N, Sacchetti M, Fischer CP, Pedersen BK (2004) Interleukin-6 is a novel factor mediating glucose homeostasis during skeletal muscle contraction. Diabetes 53: 1643-1648.

83. Ostrowski K, Schjerling P, Pedersen BK (2000) Physical activity and plasma interleukin-6 in humans--effect of intensity of exercise. Eur J Appl Physiol 83 512-515.
84. Benrick A, Wallenius V, Asterholm IW (2012) Interleukin-6 mediates exerciseinduced increase in insulin sensitivity in mice. Exp Physiol 97: 1224-1235.

85. O’Neill HM (2013) AMPK and Exercise: Glucose Uptake and Insulin Sensitivity. Diabetes Metab J 37: 1-21.

86. Cheung PC, Salt IP, Davies SP, Hardie DG, Carling D (2000) Characterization of AMP-activated protein kinase gamma-subunit isoforms and their role in AMP binding. Biochem J $346 \mathrm{Pt}$ 3: 659-669.

87. Maarbjerg SJ, Jørgensen SB, Rose AJ, Jeppesen J, Jensen TE, et al. (2009) Genetic impairment of AMPKalpha2 signaling does not reduce muscle glucose uptake during treadmill exercise in mice. Am J Physiol Endocrinol Metab 297 E924-934.

88. Lee-Young RS, Griffee SR, Lynes SE, Bracy DP, Ayala JE, et al. (2009) Skeletal muscle AMP-activated protein kinase is essential for the metabolic response to exercise in vivo. J Biol Chem 284: 23925-23934

89. Steinberg GR, O'Neill HM, Dzamko NL, Galic S, Naim T, et al. (2010) Whole body deletion of AMP-activated protein kinase beta\}2 reduces muscle AMPK activity and exercise capacity. J Biol Chem 285: 37198-37209.

90. O’Neill HM, Maarbjerg SJ, Crane JD, Jeppesen J, Jørgensen SB, et al. (2011) AMP-activated protein kinase (AMPK) beta1beta2 muscle null mice reveal an essential role for AMPK in maintaining mitochondrial content and glucose uptake during exercise. Proc Natl Acad Sci U S A 108: 16092-16097.

91. Abbott MJ, Bogachus LD, Turcotte LP (2011) AMPKît2 deficiency uncovers time dependency in the regulation of contraction-induced palmitate and glucose uptake in mouse muscle. J Appl Physiol 111: 125-134.

92. Lefort N, St-Amand E, Morasse S, Côté CH, Marette A (2008) The alpha-subunit of AMPK is essential for submaximal contraction-mediated glucose transport in skeletal muscle in vitro. Am J Physiol Endocrinol Metab 295: E1447-1454.

93. Fujii N, Hirshman MF, Kane EM, Ho RC, Peter LE, et al. (2005) AMPactivated protein kinase alpha2 activity is not essential for contraction- and hyperosmolarity-induced glucose transport in skeletal muscle. J Biol Chem 280: 39033-39041.

94. Lauritzen HP, Galbo H, Toyoda T, Goodyear LJ (2010) Kinetics of contractioninduced GLUT4 translocation in skeletal muscle fibers from living mice. Diabetes 59: 2134-2144.

95. Kelly M, Gauthier MS, Saha AK, Ruderman NB (2009) Activation of AMPactivated protein kinase by interleukin- 6 in rat skeletal muscle: association with changes in CAMP, energy state, and endogenous fuel mobilization. Diabetes 58: 1953-1960

96. Kelly M, Keller C, Avilucea PR, Keller P, Luo Z, et al. (2004) AMPK activity is diminished in tissues of IL-6 knockout mice: the effect of exercise. Biochem Biophys Res Commun 320: 449-454.

97. Ruderman NB, Keller C, Richard AM, Saha AK, Luo Z, et al. (2006) Interleukin-6 regulation of AMP-activated protein kinase. Potential role in the systemic response to exercise and prevention of the metabolic syndrome. Diabetes 55 Suppl 2: S48-54

98. Sriwijitkamol A, Ivy JL, Christ-Roberts C, DeFronzo RA, Mandarino LJ, et al. (2006) LKB1-AMPK signaling in muscle from obese insulin-resistant Zucke rats and effects of training. Am J Physiol Endocrinol Metab 290: E925-932.

99. Barnes BR, Ryder JW, Steiler TL, Fryer LG, Carling D, et al. (2002) Isoformspecific regulation of 5' AMP-activated protein kinase in skeletal muscle from obese Zucker (fa/fa) rats in response to contraction. Diabetes 51: 2703-2708.

100. Lee-Young RS, Ayala JE, Fueger PT, Mayes WH, Kang L, et al. (2011) Obesity impairs skeletal muscle AMPK signaling during exercise: role of AMPKÎ̀2 in the regulation of exercise capacity in vivo. Int J Obes (Lond) 35: 982-989

101. Musi N, Fujii N, Hirshman MF, Ekberg I, Fröberg S, et al. (2001) AMP-activated protein kinase (AMPK) is activated in muscle of subjects with type 2 diabetes during exercise. Diabetes 50: 921-927.

102. Sriwijitkamol A, Coletta DK, Wajcberg E, Balbontin GB, Reyna SM, et al. (2007) Effect of acute exercise on AMPK signaling in skeletal muscle of subjects with type 2 diabetes: a time-course and dose-response study. Diabetes 56: 836848.

103. Sauer U, Domnanich P, Preininger C (2011) Protein chip for the paralle quantification of high and low abundant biomarkers for sepsis. Anal Biochem 419: $46-52$

104. Nicklas BJ, You T, Pahor M (2005) Behavioural treatments for chronic 
Citation: Sarvas JL, Khaper N, Lees SJ (2013) The IL-6 Paradox: Context Dependent Interplay of SOCS3 and AMPK. J Diabetes Metab S13: 003. doi:10.4172/2155-6156.S13-003

Page 9 of 9

systemic inflammation: effects of dietary weight loss and exercise training. CMAJ 172: 1199-1209.

105. Bougoulia M, Triantos A, Koliakos G (2006) Plasma interleukin-6 levels, glutathione peroxidase and isoprostane in obese women before and after weight loss. Association with cardiovascular risk factors. Hormones (Athens) 5: 192-199.

106. Hansen D, Dendale P, Beelen M, Jonkers RA, Mullens A, et al. (2010) Plasma adipokine and inflammatory marker concentrations are altered in obese, as opposed to non-obese, type 2 diabetes patients. Eur J Appl Physiol 109: 397 404.

107. Tauman R, O'Brien LM, Gozal D (2007) Hypoxemia and obesity modulate plasma C-reactive protein and interleukin-6 levels in sleep-disordered breathing. Sleep Breath 11: 77-84.

108. Esposito K, Pontillo A, Giugliano F, Giugliano G, Marfella R, et al. (2003) Association of low interleukin-10 levels with the metabolic syndrome in obese women. J Clin Endocrinol Metab 88: 1055-1058.

109. Straczkowski M, Kowalska I, Nikolajuk A, Krukowska A, Gorska M (2005) Plasma interleukin-10 concentration is positively related to insulin sensitivity in young healthy individuals. Diabetes Care 28: 2036-2037.

110. Engeli S, Feldpausch M, Gorzelniak K, Hartwig F, Heintze U, et al. (2003) Association between adiponectin and mediators of inflammation in obese women. Diabetes 52: 942-947.

111. Charles BA, Doumatey A, Huang H, Zhou J, Chen G, et al. (2011) The roles of IL-6, IL-10, and IL-1RA in obesity and insulin resistance in African-Americans. J Clin Endocrinol Metab 96: E2018-2022.

112. Stowe RP, Peek MK, Cutchin MP, Goodwin JS (2010) Plasma cytokine levels in a population-based study: relation to age and ethnicity. J Gerontol A Biol Sci Med Sci 65: 429-433.

113. Goyal R, Faizy AF, Siddiqui SS, Singhai M (2012) Evaluation of TNF-ît and IL-6 Levels in Obese and Non-obese Diabetics: Pre- and Postinsulin Effects. N Am J Med Sci 4: 180-184.

114. Takala A, Nupponen I, Kylänpää-Bäck ML, Repo H (2002) Markers of inflammation in sepsis. Ann Med 34: 614-623.

115. Hack CE, De Groot ER, Felt-Bersma RJ, Nuijens JH, Strack Van Schijnde RJ, et al. (1989) Increased plasma levels of interleukin-6 in sepsis. Blood 74: 1704-1710.

116. Pickup JC, Mattock MB, Chusney GD, Burt D (1997) NIDDM as a disease of the innate immune system: association of acute-phase reactants and interleukin-6 with metabolic syndrome X. Diabetologia 40: 1286-1292.

117. Casey LC, Balk RA, Bone RC (1993) Plasma cytokine and endotoxin levels correlate with survival in patients with the sepsis syndrome. Ann Intern Med 119: $771-778$.

118. Manigrasso MR, Ferroni P, Santilli F, Taraborelli T, Guagnano MT, et al (2005) Association between circulating adiponectin and interleukin-10 levels in android obesity: effects of weight loss. J Clin Endocrinol Metab 90: 5876-5879.

119. Doughty L, Carcillo JA, Kaplan S, Janosky J (1998) The compensatory antiinflammatory cytokine interleukin 10 response in pediatric sepsis-induced multiple organ failure. Chest 113: 1625-1631.

120. Morley JJ, Kushner I (1982) Serum C-reactive protein levels in disease. Ann N Y Acad Sci 389: 406-418.

121. Siegel AJ, Stec JJ, Lipinska I, Van Cott EM, Lewandrowski KB, et al. (2001) Effect of marathon running on inflammatory and hemostatic markers. Am J Cardiol 88: 918-920, A9. 